\title{
Clinical Benefit of Early Anticoagulation in Cardioembolic Stroke
}

\author{
Sara Micheli Giancarlo Agnelli Valeria Caso Maurizio Paciaroni \\ Stroke Unit, Department of Internal Medicine, University of Perugia, Perugia, Italy
}

Key Words

Cardioembolic stroke • Nonvalvular atrial fibrillation • Anticoagulation, early

\begin{abstract}
Background: Nonvalvular atrial fibrillation is the most common source of cardiac embolism with a high reported risk of stroke and a high stroke-related mortality. A common clinical dilemma in patients with acute stroke is whether the detection of one of the major cardiac sources of emboli requires an early anticoagulation to reduce early stroke recurrence and mortality. Methods: In this review, we report on the results of clinical trials that have investigated the efficacy of early treatment for acute cardioembolic stroke. Results: Large clinical trials demonstrate that there is no evidence supporting the administration of heparin in patients with acute ischemic stroke within $48 \mathrm{~h}$ from stroke onset. Conclusions: The results of recent studies showing an advantage of the very early administration of heparin $(<3 \mathrm{~h}$ from stroke onset) should encourage clinicians to perform further trials on the efficacy of an early administration of heparin in acute cardioembolic stroke.

Copyright $\odot 2008$ S. Karger AG, Basel
\end{abstract}

(C) 2008 S. Karger AG, Basel

$1015-9770 / 08 / 0254-0289 \$ 24.50 / 0$

Fax +41613061234

E-Mail karger@karger.ch

www.karger.com
Accessible online at:

www.karger.com/ced

\section{Introduction}

Nonvalvular atrial fibrillation (NVAF) is the most common source of cardiac embolism; it is associated with a fivefold increased risk of stroke and accounts for nearly $25 \%$ of stroke occurring in patients older than 80 years [1, 2]. Atrial fibrillation (AF) has a prevalence of $0.4-0.7 \%$ in the general population [3]; the prevalence increases progressively with age, being $4 \%$ over 60 years $[4,5]$ and $15 \%$ in people older than 75 years $[6,7]$. The risk of stroke in patients with NVAF increases in the presence of hypertension or left ventricular dysfunction, prior transient ischemic attacks or stroke, mitral annular calcifications and left atrial enlargement (Stroke Prevention in Atrial Fibrillation Investigators I and II). The risk for cardioembolic infarction is estimated at $4.3 \%$ in patients with no other risk factors, and it increases to $8.5 \%$ if hypertension and hyperglycemia coexist [8]. The risk of early recurrent ischemic stroke, defined as a new embolic stroke occurring within the first 2 weeks, is higher in patients with NVAF, and the rate varies between 0.1 and $1.3 \%$ per day $[9,10]$. In patients with NVAF, it has been shown that the risk of stroke is significantly reduced by warfarin and to a lesser extent by aspirin in both primary and secondary stroke prevention $[11,12]$. In secondary prevention, several guidelines recommend long-term oral anticoagulation in patients with $\mathrm{AF}$ and recent stroke or transient ischemic attack grade IA (target international normalized ratio, 2.5; range 2-3) [13, 14]. The role of immediate

Dr. Sara Micheli

Stroke Unit, Department of Internal Medicine, University of Perugia

Ospedale Santa Maria della Misericordia

Sant' Andrea delle Fratte, IT-06126 Perugia (Italy)

Tel./Fax +39 075578 2765, E-Mail saramicheli@hotmail.it 
Table 1. Timing of anticoagulant treatment in patients with cardioembolic stroke

\begin{tabular}{|c|c|c|c|c|}
\hline \multirow[t]{2}{*}{ Interval to treat } & \multicolumn{4}{|l|}{ Type of treatment } \\
\hline & trial & anticoagulant & $\begin{array}{l}\text { duration } \\
\text { of treatment } \\
\text { days }\end{array}$ & $\begin{array}{l}\text { loading dose/ } \\
\text { monitoring } \\
\text { anticoagulation }\end{array}$ \\
\hline \multirow[t]{3}{*}{$<48 \mathrm{~h}$} & IST [16], 1997 & heparin (12,500 and 5,000 IU s.c. b.i.d.) versus no heparin & 14 & no/no \\
\hline & CESG [17], 1983 & intravenous heparin versus no heparin & 14 & NR/NR \\
\hline & TAIST [18], 2001 & tinzaparin (175 and 100 anti-Xa IU/kg) versus aspirin & 10 & no/no \\
\hline $\begin{array}{l}<48 \mathrm{~h}(32 \%<6 \mathrm{~h}, \\
68 \% 6-48 \mathrm{~h})\end{array}$ & Chamorro et al. [19], 1999 & $\begin{array}{l}\text { intravenous }(1,000 \mathrm{IU} / \mathrm{h}) \text { or subcutaneous heparin } \\
(12,500 \mathrm{IU} \text { s.c. b.i.d.) }\end{array}$ & $5-10$ & no/yes \\
\hline$<30 \mathrm{~h}$ & HAEST [20], 2000 & dalteparin (100 IU/kg s.c. b.i.d.) versus aspirin & 14 & no/no \\
\hline \multirow[t]{2}{*}{$<24 \mathrm{~h}$} & TOAST [21], 1998 & intravenous danaparoid versus placebo & 7 & yes/yes \\
\hline & FISS-bis [22], 1998 & $\begin{array}{l}\text { nadroparin ( } 85 \text { anti-Xa IU/kg s.c. once or twice a day) } \\
\text { versus placebo }\end{array}$ & 10 & no/no \\
\hline$<3 \mathrm{~h}$ & Camerlingo et al. [23], 2005 & heparin (24,000 IU i.v.) versus placebo & 5 & no/yes \\
\hline
\end{tabular}

IST = International Stroke Trial; CESG = Cerebral Embolism Study Group; TAIST = Tinzaparin in Acute Ischemic Stroke Trial; HAEST = Heparin in Acute Embolic Stroke Trial; TOAST = Trial of ORG 10172 in Acute Stroke Treatment; FISS-bis = Fraxiparine in Acute Stroke Study; NR = not recorded.

anticoagulation to reduce early recurrence and to influence functional outcome in subgroups of acute ischemic stroke and the risk-benefit ratio for acute cardioembolic stroke remain controversial. However, heparin is still used in routine clinical practice outside clinical trials. In a survey on US and Canadian neurologists, it was detected that the vast majority of clinicians used intravenous heparin for acute ischemic stroke in patients with $\mathrm{AF}$ (USA: 88\%; Canada: 84\%) [15].

The aim of this review is to clarify the efficacy of anticoagulants in early stroke management in patients with cardioembolic stroke considering the results of clinical trials.

\section{Data from Clinical Trials on Prevention of Early Recurrence of Stroke in Patients with AF}

The role of anticoagulant therapy to prevent early recurrence of stroke in patients with AF has been studied in several randomized trials (tables 1 and 2).

The Heparin in Acute Embolic Stroke Trial was a multicenter, randomized, double-blind and double-dummy study of low-molecular-weight heparin (LMWH; dalteparin $100 \mathrm{IU} / \mathrm{kg}$ s.c. twice a day) versus aspirin $(160 \mathrm{mg} /$ day) in patients with $\mathrm{AF}$ and within $30 \mathrm{~h}$ from stroke onset. In this trial 449 patients were included with the pri- mary aim to test whether treatment with LMWH was superior to aspirin for the prevention of recurrent stroke during the first 14 days. The results demonstrated no significant benefit of dalteparin: the frequency of early recurrent ischemic stroke was $8.5 \%$ in dalteparin-treated patients versus $7.5 \%$ in patients given aspirin. In patients allocated to dalteparin, there was no significantly higher prevalence of progression of symptoms within the first $48 \mathrm{~h}$ and more death after 14 days; there was a significantly higher frequency of extracerebral hemorrhages. There was no difference in outcome at 3 months in the two groups [20]. A recent post hoc subgroup analysis was conducted on 431 patients with acute ischemic stroke and AF included in the Heparin in Acute Embolic Stroke Trial, using clinical, hemostatic (D-dimer, prothrombin fragments 1 and 2, soluble fibrin monomer) and inflammatory (C-reactive protein) variables collected on admission. However, the study failed to identify any patient subgroup that did better with early treatment with LMWH compared to aspirin, and it did not support the use of LMWH in any subgroup with acute ischemic stroke and AF [24].

The International Stroke Trial studied the occurrence of major clinical events within 14 days among a total number of 19,435 patients with acute ischemic stroke, 3,169 of whom (17\%) had AF. This study examined the effects of treatment with subcutaneous unfractionated 
Table 2. Functional outcome events at follow-up in patients with cardioembolic stroke

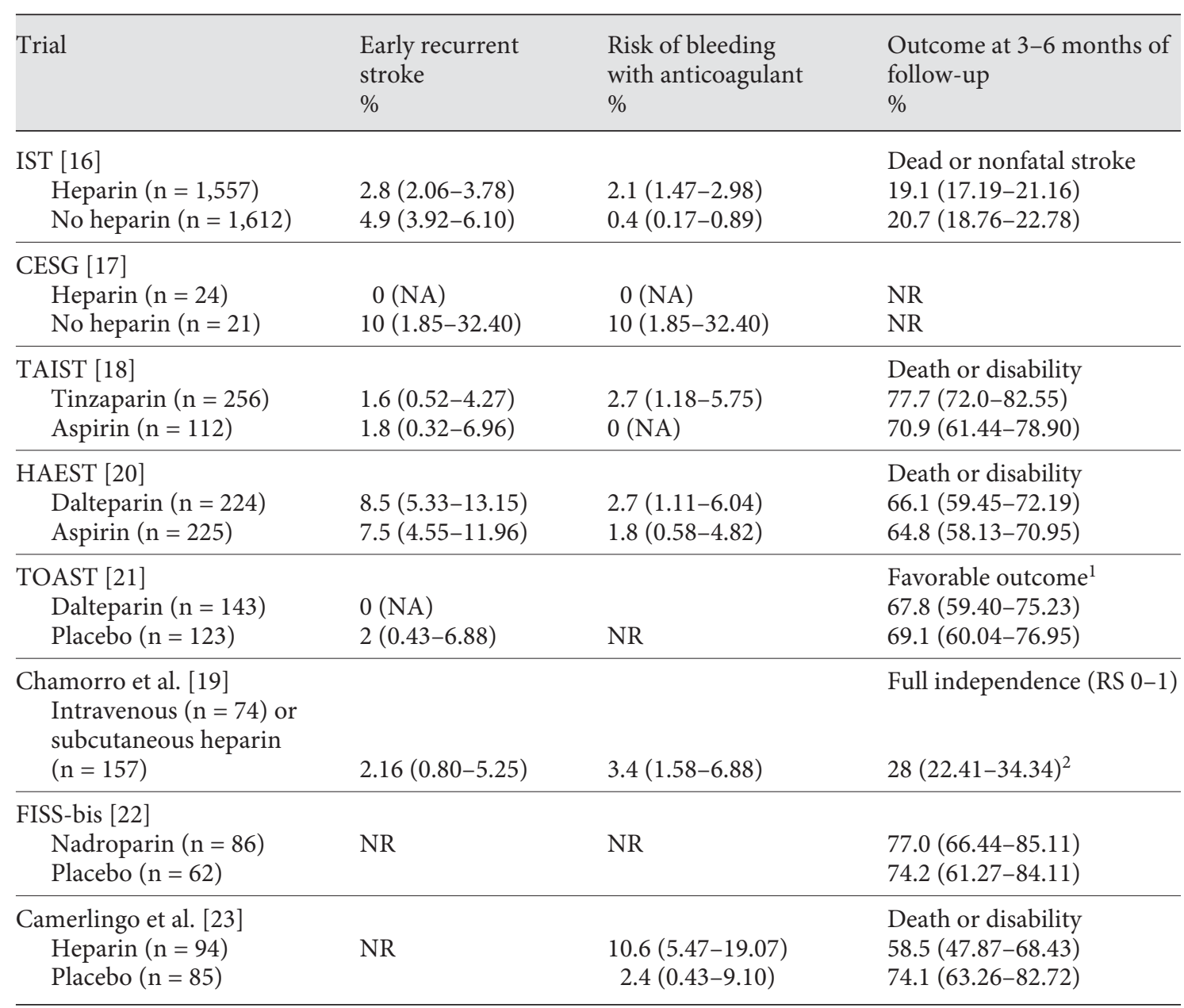

Figures in parentheses indicate 95\% confidence intervals. For trial abbreviations, see table 1; NA = not assessed; $\mathrm{NR}=$ not recorded; $\mathrm{RS}=$ Rankin Scale.

${ }^{1}$ Defined as a score of 1 or 2 on the Glasgow Outcome Scale and a score of 12-20 on the modified Barthel Index.

${ }^{2}$ Using logistic regression analysis, early administration of heparin $(<6 \mathrm{~h})$ was a positive predictor of recovery (odds ratio 1.7; 95\% confidence interval 1.1-2.5).

heparin (UFH) started within $48 \mathrm{~h}$ and continued until 14 days after stroke onset. Half of the patients were allocated to UFH (5,000 or 12,500 IU twice a day) and half to avoid heparin; in each of these groups, half of the patients were randomly assigned to aspirin $300 \mathrm{mg} /$ day. Within 14 days in the heparin-treated group there were no significant differences in deaths compared with the no-heparin group, but there were significant differences in hemorrhagic stroke and extracranial bleeding. Among patients with AF, 784 were allocated to UFH 12,500 IU s.c. b.i.d., 773 to UFH 5,000 IU s.c. b.i.d., 1,612 to no heparin. In patients with ischemic stroke and AF there was a rate

Early Anticoagulation in Cardioembolic Stroke of recurrent ischemic stroke of $2.8 \%$ in heparin-treated patients compared with $4.9 \%$ of the no-heparin group $(\mathrm{p}<0.01)$, and this means that there were 21 events prevented per 1,000 patients treated but this was offset by 16 more hemorrhagic strokes [16]. Heparin significantly reduced the risk of recurrence after 2 weeks in AF patients but the increased risk of bleeding (2.1 vs. $0.4 \%)$ neutralized the potential benefit.

In the Trial of ORG 10172 in Acute Stroke Treatment, a low-molecular-weight heparinoid, ORG 10172 (danaparoid sodium), was administered by an intravenous bolus dose within $24 \mathrm{~h}$ from onset of stroke symptoms, fol- 
lowed by a continuous infusion for 7 days, adjusting the rate of infusion to the anti-factor-Xa activity. The objective of this study was to test outcome at 7 days and 3 months after stroke [21]. The data suggest that at 7 days there was a favorable outcome in patients treated with LWMH compared to the control group, with rates of favorable outcome of $33.9 \%$ in the patients receiving ORG 10172 and $27.8 \%$ in the placebo group; at 3 months after stroke the rate of favorable outcome became $48 \%$ in each group, and only in the subgroup of stroke due to largeartery disease was there a significant difference in better outcome among patients who received ORG 10172 compared to placebo-treated patients. In this study the severity of stroke at baseline strongly predicted a worse outcome at 3 months, and it was not influenced by the 2 treatment groups. Bleeding was more frequent and severe in the group receiving $\mathrm{LMWH}$, and at 3 months the rate of recurrence of ischemic strokes, systemic embolism, myocardial infarction, deep-vein thrombosis and pulmonary embolism was higher in the placebo group. However, in the patients with cardioembolic stroke, the risk of early recurrence of ischemic events was not different from the patients with stroke due to other causes. The trial suggests that early administration of antithrombotic drugs in patients with cardioembolic stroke has a limited impact on lowering the risk of recurrence compared to long-term anticoagulation, but at the same time it suggests an efficacy in improving the 3 -month outcome from early treatment with ORG 10172 in patients with largeartery atherosclerosis. Finally, the TOAST confirms that early anticoagulation of patients with severe strokes increases the risk of symptomatic intracranial bleeding which is correlated with the patient's age and level of anticoagulation.

In the Tinzaparin in Acute Ischemic Stroke study, the administration of low (100 anti-Xa U/kg) and high (175 anti-Xa U/kg) tinzaparin doses was compared with aspirin $300 \mathrm{mg}$ in a randomized blinded trial performed within $48 \mathrm{~h}$. The reported results showed a proportional increase in extracranial and intracranial hemorrhage in the groups receiving high and low doses of anticoagulants compared with aspirin [18].

The Fraxiparine in Ischemic Stroke Study revealed that high and low doses of nadroparin were not more effective than placebo. Moreover, in the Cerebral Embolism Study Group, $10 \%$ of patients on heparin (2 out of 21 ) presented a symptomatic cerebral hemorrhage compared with those not receiving heparin $[17,22]$. Finally, the trials did not show an improved outcome and a reduction in death with the administration of anticoagulants.
All of these trials mentioned above do not support the early use of heparin but the time window from stroke onset to treatment was $12-48 \mathrm{~h}$. The benefit from an earlier heparin use in acute stroke management has been reported in a study by Chamorro et al. [19] in 231 patients with stroke and NVAF treated with intravenous or subcutaneous heparin, with a delay of the initiation of therapy of less than $6 \mathrm{~h}$ from stroke onset in 74 patients and between 6 and $48 \mathrm{~h}$ in 157 patients. The results showed that early treatment with heparin $(<6 \mathrm{~h})$ was an independent factor for a better functional outcome [19].

A randomized trial performed by Camerlingo et al. [23], using heparin within the first $3 \mathrm{~h}$ after the onset of ischemic stroke, suggests that intravenous heparin could be helpful in the early treatment of acute nonlacunar stroke, even with an increased frequency of intracranial symptomatic brain hemorrhages and more major extracerebral bleeding. In this study, patients with a total or a partial clinical syndrome, according to Bamford's classification [25], were assigned to receive for 5 days a continuous infusion of 24,000 IU of intravenous heparin or an equal quantity of saline; after 5 days both groups of patients were given $100 \mathrm{mg} /$ day of aspirin or an oral anticoagulant (with a target international normalized ratio between 2.0 and 3.0) in patients with cardioembolic stroke. The total number of patients included in the study was 418, and AF was found in 173 patients (41.3\%): the results of this study showed that patients allocated to heparin were more likely to be independent and alive at 90 days, with an absolute risk reduction of about $10 \%$, suggesting that heparin could have an efficacy in acute ischemic nonlacunar stroke - as long as the treatment is started within a short time interval after the stroke onset. After 3-6 months of follow-up, $58 \%$ of patients with AF given heparin were dead or disabled compared with $74 \%$ of patients allocated to the placebo group with an increased risk of cerebral hemorrhage in the anticoagulant group (10.6 vs. $2.4 \%$ ). This study, according to the results of Chamorro et al. [19], supports the efficacy of starting anticoagulation treatment within 3-6 h from stroke onset.

A recent meta-analysis, including the randomized studies described above, found that anticoagulants were associated with nonsignificant reductions in recurrent stroke within 2 weeks (3.2 vs. 5.0\%) as well as with significant increases in symptomatic intracranial bleeding ( 2.5 vs. $0.8 \%$; tables 3 and 4 ) [26]. This analysis suggests that death and disability after 6 months are not reduced by early anticoagulant treatment in patients with acute ischemic stroke due to cardioembolism. 
Table 3. Hemorrhagic transformation in trials comparing anticoagulants with other treatments for the initial treatment of acute cardioembolic stroke

a Outcome: hemorrhagic stroke (anticoagulants vs. aspirin or placebo)

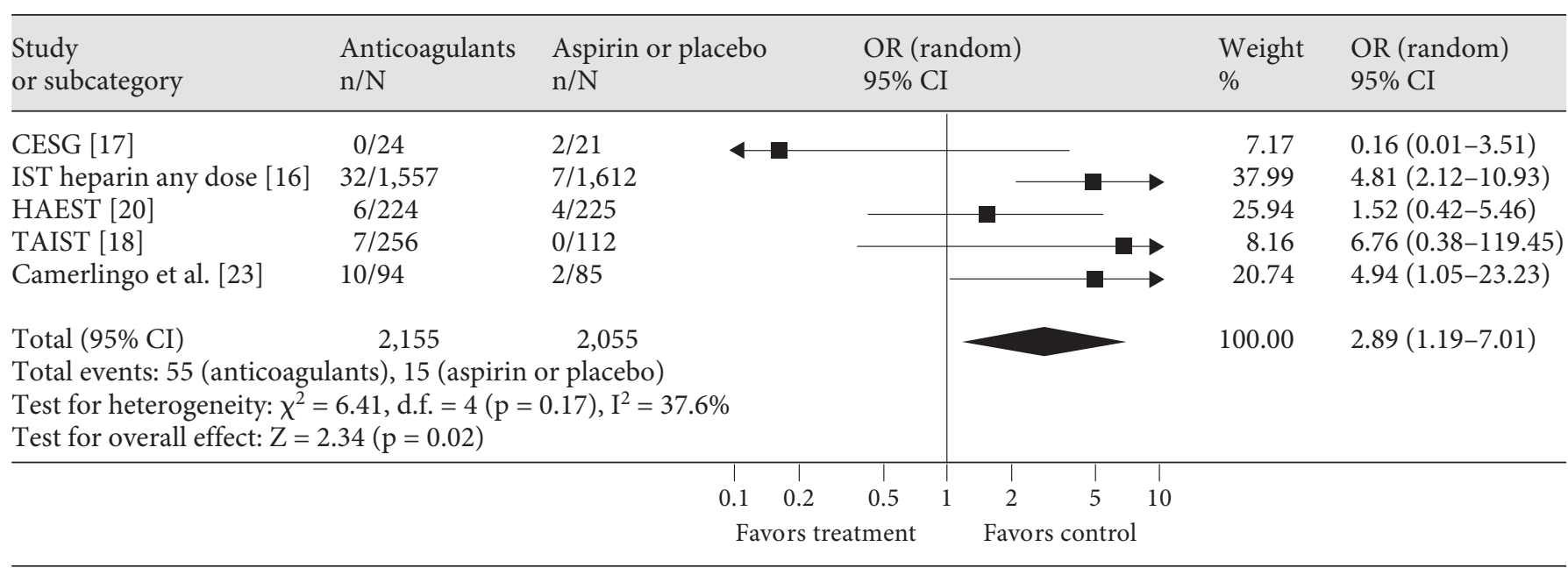

b Outcome: hemorrhagic stroke (anticoagulants vs. aspirin)

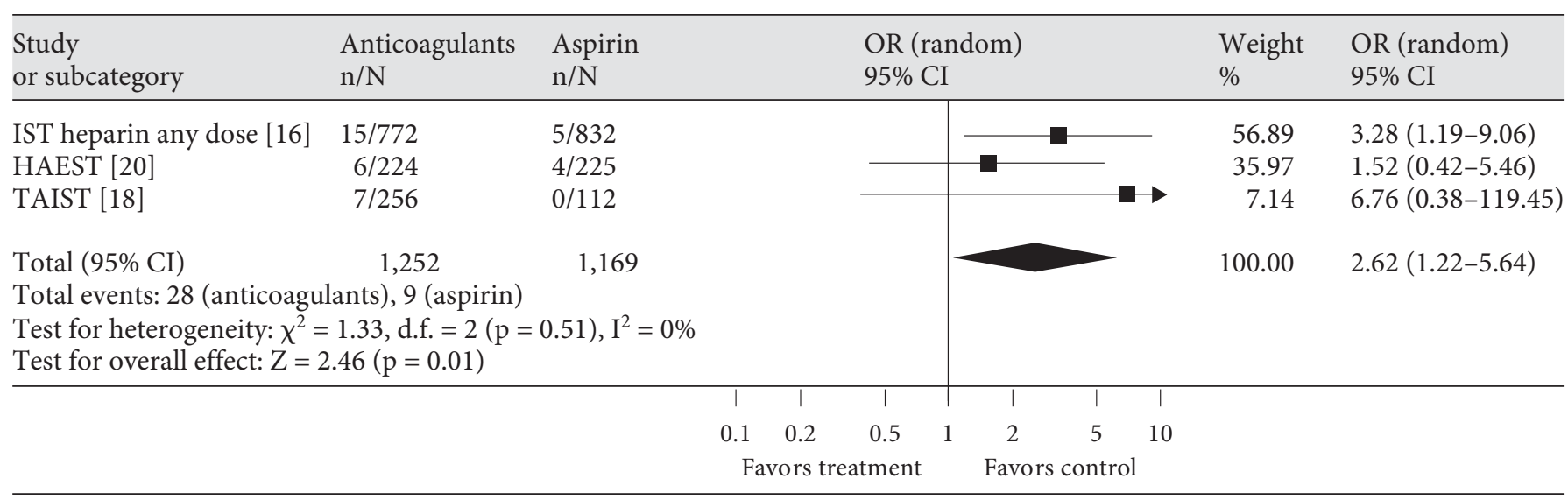

c Outcome: hemorrhagic stroke (anticoagulants vs. placebo)

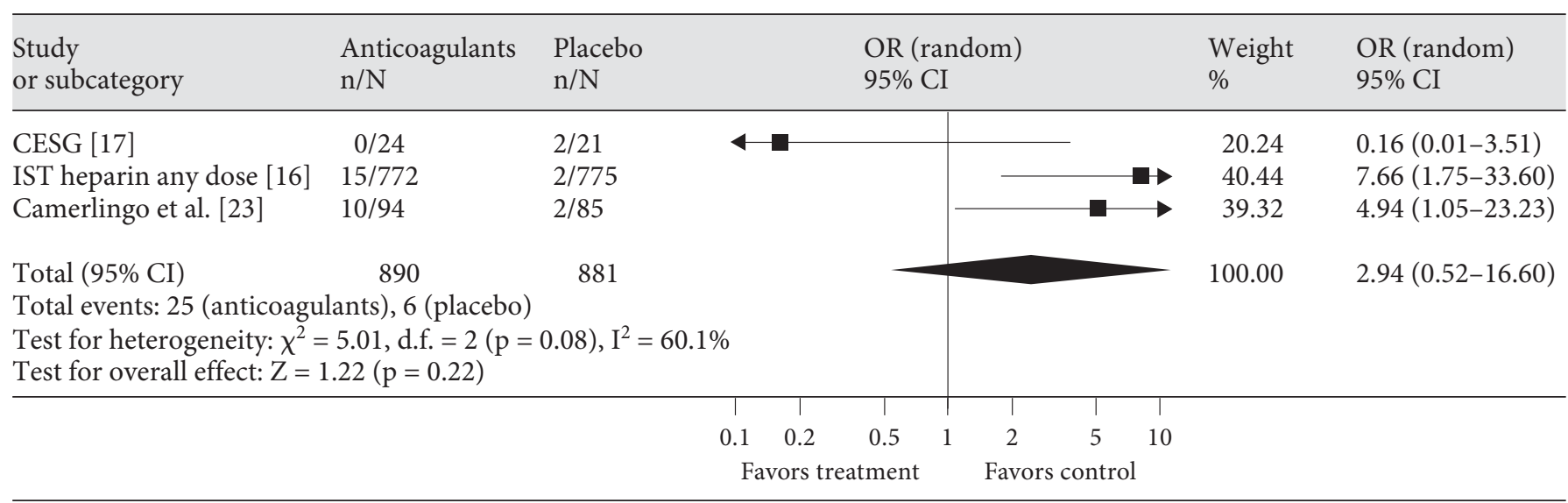

$\mathrm{OR}=$ Odds ratio; $95 \%$ confidence intervals, indicated in parentheses; $\mathrm{n} / \mathrm{N}=$ patient number out of total number, for trial abbreviations, see table 1 . 
Table 4. Early recurrent stroke in trials comparing anticoagulants with other treatments for the initial treatment of acute cardioembolic stroke

a Outcome: recurrent stroke (anticoagulants vs. aspirin or placebo)

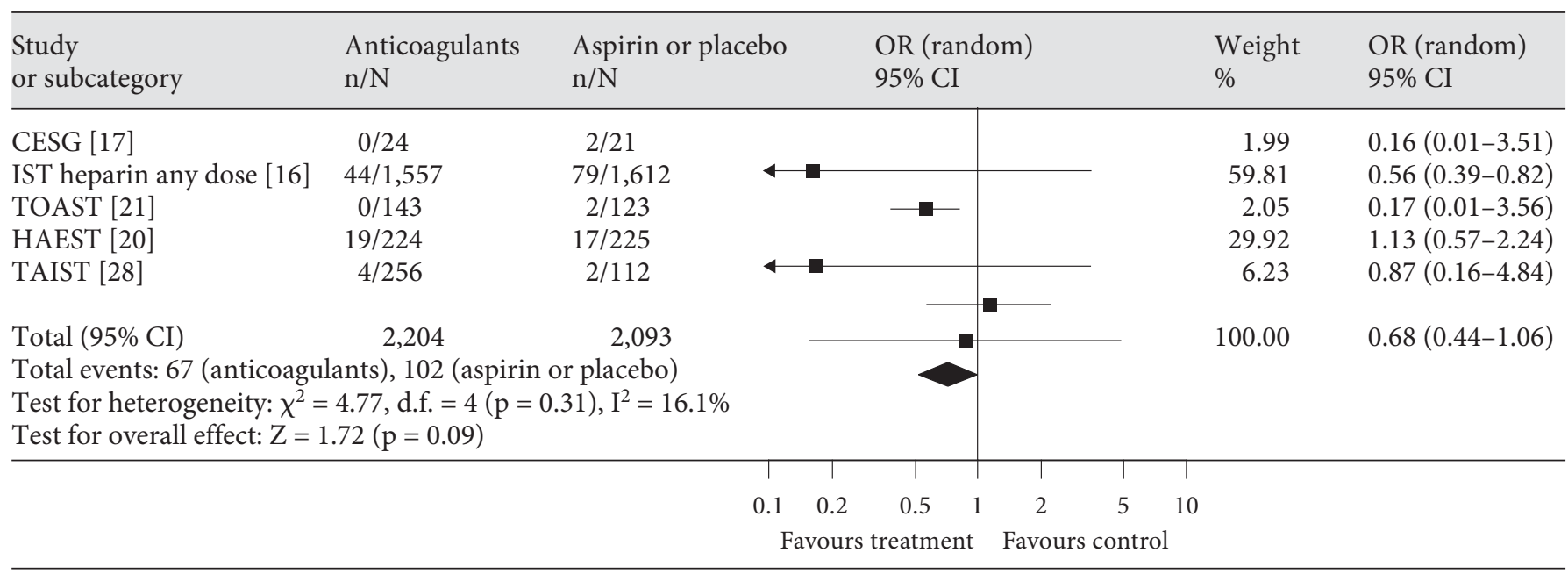

b Outcome: recurrent stroke (anticoagulants vs. aspirin)

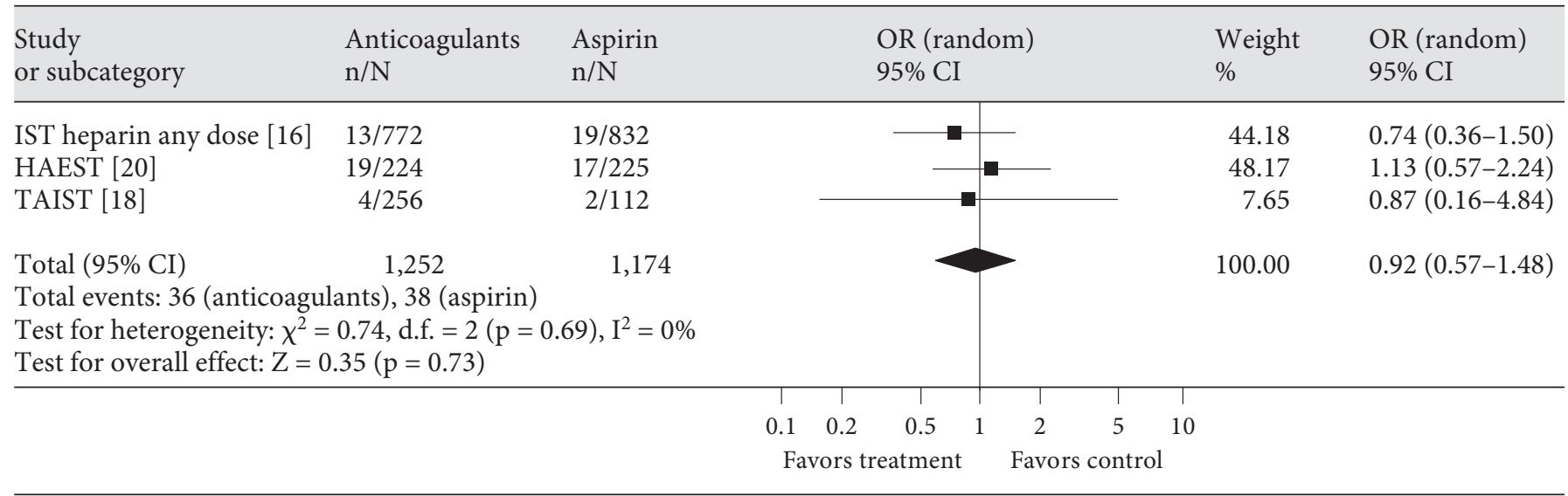

c Outcome: recurrent stroke (anticoagulants vs. placebo)

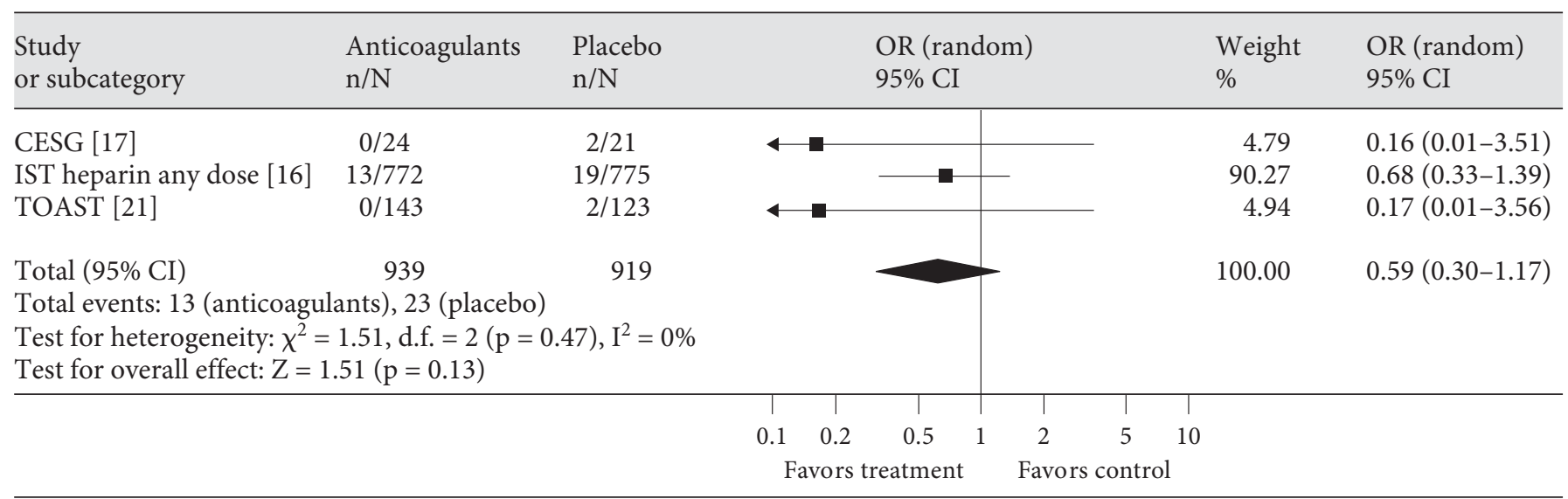

$\mathrm{OR}=$ Odds ratio; $95 \% \mathrm{CI}=$ confidence intervals, indicated in parentheses; $\mathrm{n} / \mathrm{N}$ = patient number out of total number; for trial abbreviations, see table 1 . 


\section{Discussion}

Large clinical trials demonstrate that there is no evidence supporting the administration of anticoagulants in patients with acute ischemic stroke within $48 \mathrm{~h}$ from stroke onset, considering the increased risk of bleeding. However, as reported in recent surveys, the use of anticoagulants in early ischemic stroke in clinical practice is not uncommon.

Caplan [27] sustains that heparin should not be indiscriminately given in acute ischemic stroke because of lack of evidence; even so he usually administers heparin in selected patients such as those with cardioembolic stroke. However, Chamorro [28] and Sandercock [29] assert that current data from randomized trials are not sufficient enough to support the use of UFH in any subtype of acute ischemic stroke. Other authors use immediate anticoagulation in exceptional circumstances such as recurrent embolism or echocardiographic evidence of left atrial or ventricular thrombus [30]. It is to be noted here that none of the trials used a monitoring anticoagulation protocol. The question here is whether there is bioequivalence between different anticoagulation agents and modes of administration.

Emergency anticoagulation could have a role in the prevention of deep-vein thrombosis and pulmonary embolism, considering that one third of bedridden patients who have a paralysed lower limb might develop a deepvein thrombosis and secondary pulmonary embolism. This is a major cause of morbidity and mortality after ischemic stroke $[31,32]$. In the International Stroke Trial, UHF-treated patients had fewer pulmonary emboli recorded within 14 days $(0.5$ vs. $0.8 \% ; \mathrm{p}=0.02)$ but at 6 months the rate of deaths or dependent patients was iden- tical. In a meta-analysis, the rates of pulmonary embolism in patients with cardioembolic stroke were similar in patients treated either with anticoagulants or aspirin [26].

In clinical trials on thrombolytic therapy for acute ischemic stroke, approximately $20-30 \%$ of patients had AF $[33,34]$. Thrombolysis given within $3 \mathrm{~h}$ of stroke onset appears to offer a benefit for patients with AF with acute ischemic stroke. The option of treating with thrombolysis patients with acute ischemic stroke and AF is limited by a large volume of brain infarcts, old age and the likelihood of symptomatic brain hemorrhage. However, some studies, after adjustment for extent and severity of ischemia, have demonstrated that AF is not associated with secondary hemorrhagic transformation after thrombolysis [35]. Further clinical trials in the 3-hour time window need to compare anticoagulant treatment with thrombolysis.

\section{Conclusions}

Early aspirin followed by vitamin $\mathrm{K}$ antagonists for long-term secondary prevention is reasonable in patients with acute ischemic stroke of cardioembolic origin to prevent early recurrence or to improve functional outcome. The results of recent studies showing an advantage of the very early administration of heparin $(<3 \mathrm{~h}$ from stroke onset) and data regarding the property of heparin on the modulation of inflammatory pathways encourage clinicians to perform further trials on the efficacy of early administration of heparin in acute cardioembolic stroke.

\section{References}

- 1 Wolf PA, D’Agostino RB, Belanger AJ, Kannel WB: Probability of stroke: a risk profile from the Framingham Study. Stroke 1991;22: 312-318.

$\checkmark 2$ Wolf PA, Dawber TR, Thomas HE Jr, Kannel WB: Epidemiological assessment of chronic atrial fibrillation and the risk of stroke: the Framingham Study. Neurology 1978;28: 973-977.

3 Hart RG, Sherman DG, Easton JD, et al: Prevention of stroke in patients with nonvalvular atrial fibrillation: views and reviews. Neurology 1998;51:674-681.
4 Hart RG: Antithrombotic therapies for stroke prevention in atrial fibrillation; in Barnett HJM, Bogousslavsky J, Meldrum H (eds): Advances in Neurology. Philadelphia, Lippincott Williams \& Wilkins, 2003, vol 2, pp 249-262.

5 Staszewski J, Staszewska M, Kotowicz J, et al: Cerebrovascular incidents differ in patients with permanent and paroxysmal atrial fibrillation. Cerebrovasc Dis 2006;22:5-6.

6 Howard PA: Guidelines for stroke prevention in patients with atrial fibrillation. Drug 1999;58:997-1009.

\footnotetext{
7 Bornstain N, Corea F, Gallai V, Parnetti L: Heart-brain relationship: atrial fibrillation and stroke. Clin Exp Hypertens 2002;24: 493-499.

$\checkmark 8$ Sacco RL, Foulkes MA, Mohr JP, Wolf PA, Hier DB, Price TR: Determinants of early recurrence of cerebral infarction: the stroke databank. Stroke 1989;20:983-989.

$\checkmark 9$ Hart RG, Coull BM, Hart D: Early recurrent embolism associated with nonvalvular atrial fibrillation: a retrospective study. Stroke 1983;14:688-693.
} 
10 Kelley RE, Berger JR, Alter M, Kovacs AG: Cerebral ischemia and atrial fibrillation: prospective study. Neurology 1984;34:12851291.

-11 Gottlieb LK, Salem-Schatz S: Anticoagulation in atrial fibrillation: does efficacy in clinical trials translate into effectiveness in practice? Arch Intern Med 1994;154:19451953.

$\checkmark 12$ McCrory DC, Matchar DB, Samsa G, et al: Physician attitudes about anticoagulation for nonvalvular atrial fibrillation in the elderly. Arch Intern Med 1995;155:277-281.

-13 Albers GW, Amarenco P, Easton JD, Sacco RL, Teal P: Antithrombotic and thrombolytic therapy for ischemic stroke: the seventh ACCP conference on antithrombotic and thrombolytic therapy. Chest 2004;126:483S$512 S$.

- 14 Sacco RL, Adams R, Albers G, Alberts MJ Benavente O, Furie K, Goldstein LB, Gorelick P, Halperin J, Harbaugh R, Johnston SC, Katzan I, Kelly-Hayes M, Kenton EJ, Marks M, Schwamm LH, Tomsick T: Guidelines for prevention of stroke in patients with ischemic stroke or transient ischemic attack: a statement for healthcare professionals from the American Heart Association/American Stroke Association Council on stroke. Stroke 2006;37:577-617.

15 Al Sadat A, Sanbulli M, Chaturvedi S: Use of intravenous heparin by North American neurologists: do the data matter? Stroke 2002;33:1574-1577.

16 Saxena R, Lewis S, Berge E, Sandercock P, Koudstaal PJ, International Stroke Trial Collaborative Group: Risk of early death and recurrent stroke and effect of heparin in 3,169 patients with acute ischemic stroke and atrial fibrillation in the International Stroke Trial. Stroke 2001;32:2333-2337.
7 CESG: Cerebral Embolism Study Group. Immediate anticoagulation of embolic stroke: a randomized trial. Stroke 1983;14:668-676.

18 Bath PM, Lindenstrom E, Boysen G, De Deyn P, Friis P, Leys D, Marttila R, Olsson J, O’Neill D, Orgogozo J, Ringelstein B, van der Sande J, Turpie AG: Tinzaparin in acute ischemic stroke (TAIST): a randomized aspirincontrolled trial. Lancet 2001;358:702-710.

19 Chamorro A, Vila N, Ascaso C, Blanc R: Heparin in acute stroke with atrial fibrillation. Arch Neurol 1999;56:1098-1102.

20 Berge E, Abdelnoor M, Nakstad PH, Sandset PM, the HAEST Study Group: Low molecular-weight heparin versus aspirin in patients with acute ischemic stroke and atrial fibrillation: a double-blind randomised study. Lancet 2000;355:1205-1210.

-21 Publications Committee for the Trial of ORG 10172 in Acute Stroke Treatment (TOAST) Investigators: Low molecular weight heparinoid, ORG 10172 (danaparoid), and outcome after acute ischemic stroke: a randomized controlled trial. JAMA 1998;279:12651272.

22 Hommel M, FISS-bis Investigators Group: Fraxiparine in ischemic stroke study (FISS bis) (abstract). Cerebrovasc Dis 1998;8 (suppl):19.

23 Camerlingo M, Salvi P, Belloni G, et al: Intravenous heparin started within the first 3 hours after onset of symptoms as a treatment for acute nonlacunar hemispheric cerebral infarctions. Stroke 2005;36:2415-2420.

24 O’Donnel MJ, Berge E, Sandset MP: Are there patients with acute ischemic stroke and atrial fibrillation that benefit from low molecular weight heparin? Stroke 2006;37:452455.

25 Bamford J, Sandercock P, Dennis M, Burn J, Warlow C: Classification and natural history of identifiable subtypes of cerebral infarction. Lancet 1991;337:1521-1526.
26 Paciaroni M, Agnelli G, Micheli S, Caso V: Efficacy and safety of anticoagulant treatment in acute cardioembolic stroke: a metaanalysis of randomised controlled trials. Stroke 2007;38:423-430.

27 Caplan LR: Resolved: heparin may be useful in selected patients with brain ischemia. Stroke 2003;34:230-231.

28 Chamorro A: Immediate anticoagulant for acute stroke in atrial fibrillation: yes. Stroke 2006;37:3052-3053.

-29 Sandercock P: Full heparin anticoagulation should not be used in acute ischemic stroke. Stroke 2003;34:231-232.

30 Davis SM, Donnan GA: Immediate anticoagulant for acute stroke in atrial fibrillation: no, but. Stroke 2006;37:3055.

31 Bath PM, Iddenden R, Bath FJ: Low-molecular-weight heparins and heparinoids in acute ischemic stroke: a meta-analysis of randomized controlled trials. Stroke 2000;31:17701778.

32 Lensing AW: Anticoagulation in acute ischemic stroke: deep vein thrombosis prevention and long-term outcomes. Blood Coagul Fibrinolysis 1999;10(suppl 2):S123-S127.

33 Yoneda Y, Mori E, Uehara T, Tabuchi M: Nonvalvular atrial fibrillation in acute ischemic stroke candidates for thrombolytic therapy. Cerebrovasc Dis 1997;7:357-358.

34 Albers GW, Bates VE, Clark WM, Bell R, et al: Intravenous tissue-type plasminogen activator for treatment of acute stroke. JAMA 2000;283:1145-1150.

35 Jaillard A, Cornu C, Durieux A, Moulin T, et al: Hemorrhagic transformation in acute ischemic stroke: the MAST-E Study. Stroke 1999;30:1326-1332. 